\title{
Evaluation of Oxalate Concentration in the U.S. Spinach Germplasm Collection
}

\author{
Beiquan Mou ${ }^{1}$ \\ U.S. Department of Agriculture, Agricultural Research Service, 1636 East \\ Alisal Street, Salinas, CA 93905
}

Additional index words. breeding, germplasm screening, nutritional quality, oxalic acid, Spinacia oleracea, Spinacia tetrandra, Spinacia turkestanica

\begin{abstract}
The entire USDA spinach (Spinacia oleracea) germplasm collection (338 accessions) and 11 commercial cultivars were screened for oxalate concentration. There were significant differences in oxalate concentration among the genotypes evaluated, ranging from $5.3 \%$ to $11.6 \%$ on a dry weight basis. The low-oxalate genotypes identified in our experiments are all $S$. oleracea. None of the two $S$. tetrandra and four $S$. turkestanica accessions screened had low levels of oxalate. Two accessions from Syria, PI 445782 (cultivar name Shami) and PI 445784 (cultivar name Baladi), consistently had low oxalate concentration. When expressed on a fresh weight basis, oxalate concentration may be affected by the moisture content of the plant. Oxalate concentration had little correlation with leaf types (flat or savoy) and leaf weight per plant. With the genetic variation and sources of low oxalate concentration found, breeding of spinach for a low level of oxalate seems feasible.
\end{abstract}

Spinach is one of the most desirable dark green, leafy vegetables as a result of its high content of beta carotene (provitamin A), lutein, folate, vitamin C, calcium, iron, phosphorous, and potassium (Morelock and Correll, 2008). Spinach is currently grown on $\approx 25,000$ ha in the United States annually for both fresh and processed markets with a crop value of $\$ 190$ million (National Agricultural Statistics Service, USDA, 2006).

In addition to its high nutrient content, spinach is also known to have a greater amount of oxalic acid than most crops. Oxalic acid is an organic acid present in fungi, algae, lichens, higher plants, and animals, including humans (Oke, 1969) formed as a secondary metabolite of vitamin $\mathrm{C}$ (Hodgkinson, 1977). Oxalic acid exists as free acid and mineral crystals that include soluble salts of potassium, sodium, and zinc and insoluble salts of calcium, magnesium, and iron. Insoluble oxalate crystals formed in the gut are not absorbed and are carried out with the feces, thus reducing the bioavailability and absorption of calcium and iron in

Received for publication 3 Apr. 2008. Accepted for publication 22 May 2008.

I thank Darren Hasegawa, Carlee Hunzie, JoAnn Tanaka, and Uriel Gutierrez for technical assistance and Susanne Klose and Chunxiao Jiang for critical review and discussion of the manuscript. I also thank the North Central Regional Plant Introduction Station (NCRPIS) of the U.S. Dept. of Agriculture (USDA), Ames, IA, and seed companies for providing spinach seeds for this research. Mention of a trade name, proprietary product, or vendor does not constitute an endorsement, guarantee, or warranty by the USDA and does not imply its approval to the exclusion of other products or vendors that may be suitable.

${ }^{1}$ To whom reprint requests should be addressed; e-mail beiquan.mou@ars.usda.gov diets (Bataille and Fournier, 2001). Human urine always contains small levels of calcium oxalate (Oke, 1969) that may be deposited in the kidneys of certain people as a common form of kidney stones (Massey et al., 1993). In healthy adults, with U.S.- or Europeantype diets, $90 \%$ of oxalic acid excreted in the urine comes from endogenous metabolic synthesis (Massey et al., 1993). However, reduction of foods with high levels of oxalic acid is recommended as a dietary change for kidney stone-formers.

Besides spinach, other vegetables with a high level of oxalic acid include amaranth, cassava, chives, parsley, and purslane (USDA, 1984). Calcium oxalate is the form principally found in spinach (Kitchen et al., 1964). Oxalic acid oxidase catalyzes the breakdown of oxalic acid into carbon dioxide and hydrogen peroxide. Although the enzyme is present in spinach leaves, it is usually inactive (Oke, 1969). Studies on beet root extracts showed that the sole inhibiting factor was nitrate, and a low concentration of nitrate was sufficient to inhibit the enzyme (Oke, 1969). Palaniswamy et al. (2004) found that the oxalic acid concentrations in purslane leaves were reduced with increasing ammonium to nitrate ratios in hydroponic solutions. In soil, however, nitrifying microorganisms are very abundant and convert the ammonium first into nitrite and then into nitrate.

Kaminishi and Kita (2006) found that spinach oxalate concentration on a fresh weight basis was the lowest in the fall, followed by the summer and the spring, and was the highest in the winter. Some investigators found oxalate increased with plant age (Hodgkinson, 1977), whereas others reported spinach oxalate concentration decreased with age (Okutani and Sugiyama, 1994). Okutani and Sugiyama (1994) also found that the higher the leaf position from the plant base, the lower the oxalate concentration in three spinach cultivars. Oxalic acid contents were lower in stems and petioles than in leaf blades (Elia et al., 1998; Maynard et al., 1976; Pandey and Kalloo, 1993).

Genetic variation in spinach oxalate content has been reported. Kitchen et al. (1964) found significant differences among 39 breeding lines, hybrids, and $\mathrm{F}_{2}$ populations in the amount of anhydrous oxalic acid present. In a study of 182 open-pollinated and $F_{1}$ hybrid cultivars and breeding lines available in Japan, Kaminishi and Kita (2006) found that fast-growing cultivars contained higher nitrate and lower oxalate, whereas slowgrowing cultivars had lower nitrate and higher oxalate concentrations. Conversely, Kohman (1939) observed no significant differences in the oxalate content in 53 commercial and experimental varieties, averaging $9.0 \%$ anhydrous oxalic acid on a dry weight basis. Anhydrous oxalic acid levels as high as $15 \%$ of the dry weight have been reported in spinach (Moir, 1953).

Reducing the oxalic acid concentration would increase the nutritional value and consumer acceptance of spinach. A breeding program for improvement must start from germplasm evaluation to identify sources of low oxalate content. This experiment was conducted to screen the USDA spinach germplasm collection for oxalate concentration and to study the possible association of oxalate content with other traits.

\section{Materials and Methods}

Experiments were conducted at the Agricultural Research Station of the USDA, Salinas, CA (lat. 36 $40^{\prime} \mathrm{N}$, long. 121 $36^{\prime}$ W). During the course of these studies, the entire USDA spinach collection from NCRPIS plus 11 commercial cultivars were screened for oxalate concentration. The USDA collection includes 332 accessions of cultivated spinach, four accessions of $S$. turkestanica, and two accessions of S. tetran$d r a$. Eight seeds from each genotype were planted in a plastic pot $(10 \times 10 \times 10 \mathrm{~cm})$ filled with soil in a greenhouse on 24 Jan. 2006. The experimental design was a randomized complete block with two replications.

After plant emergence, each pot was fertilized weekly with $50 \mathrm{~mL}$ of a soluble fertilizer as a combination of ammonium phosphate, potassium nitrate, and urea (20N-8.8P-16.6K; Nortrace, Ltd., Greeley, $\mathrm{CO})$ at a concentration of $0.8 \mathrm{~g} \cdot \mathrm{L}^{-1}$. The nitrogen component consists of $2.9 \%$ ammoniac $\mathrm{N}, 5.0 \%$ nitrate $\mathrm{N}$, and $12.1 \%$ urea $\mathrm{N}$. The air temperature varied between 8 and $27{ }^{\circ} \mathrm{C}$ night/day and the daylength changed from $10 \mathrm{~h} 10 \mathrm{~min}$ to $11 \mathrm{~h} 22 \mathrm{~min}$ during the experiment (Anonymous, 2008a). Four weeks after planting, chlorophyll content of five randomly selected mature leaves in each pot was measured by using a chlorophyll meter (Minolta Chlorophyll Meter SPAD502; Spectrum Technologies, Plainfield, IL) and the readings were averaged for each pot. Five weeks after planting (Fig. 1), all leaves 


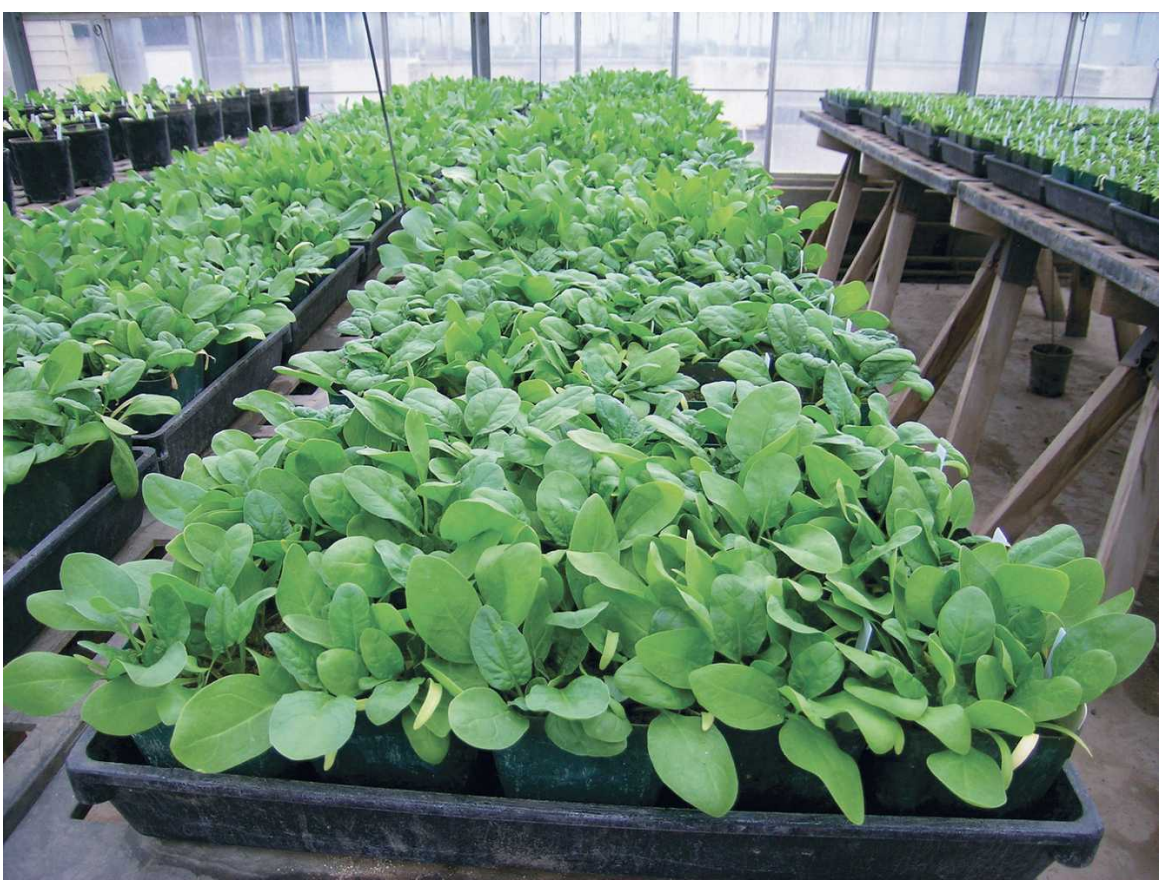

Fig. 1. Plants of different spinach accessions in the 2006 screening experiment just before harvest (5 weeks after planting)

in a pot were harvested without petioles in the morning and fresh weight of the leaves was determined. Harvested leaves were dried at $60{ }^{\circ} \mathrm{C}$ for $24 \mathrm{~h}$ before being weighed for dry weight.

The leaves were redried at $60{ }^{\circ} \mathrm{C}$ overnight, broken into small pieces by hand, and mixed. A 0.01-g leaf sample was homogenized in $5 \mathrm{~mL}$ deionized water for 6 min with a homogenizer (Ultra-turrax T25; Janke \& Kunkel, IKA-Labortechnik, Staufen, Germany) at 24,000 rpm. The sample was diluted with $5 \mathrm{~mL}$ EDTA (10 mm, pH 7.6) and centrifuged at $1,500 \mathrm{rcf}$ for $5 \mathrm{~min}$. The oxalate concentration in the supernatant was determined using an oxalate kit (Procedure No. 591; Trinity Biotech, St. Louis) as described by Palaniswamy et al. (2004). The oxalate concentrations were calculated on both fresh and dry weight bases.

From the initial screening, 40 putative accessions with low oxalate concentration were identified for further testing. These genotypes, plus 13 accessions with high oxalate concentration and the 11 commercial cultivars, were planted on 22 Jan. 2007 for another test using methods described previously. The experimental design was a randomized complete block with five replications. The air temperature was $12{ }^{\circ} \mathrm{C}$ night to $27^{\circ} \mathrm{C}$ day in the greenhouse.

Fresh leaf weight from each pot was divided by the number of plants in the pot to derive leaf weight per plant. Data were analyzed by analysis of variance using the general linear model procedure of JMP v. 5 (SAS Institute, Cary, NC). Genotype was considered the fixed effect, and replication was considered the random effect. For comparisons between genotypes, least significant differences were calculated with an error rate types of all genotypes in the 2006 experiment were rated on a 1 to 4 scale ( $1=$ flat, $2=$ semiflat, $3=$ semisavoy, and $4=$ savoy). A correlation matrix for genotype means was calculated for all variables using the multivariate platform of JMP.

\section{Results and Discussion}

There were significant differences in leaf weight per plant, chlorophyll content, moisture percent, and oxalate concentration of $P=0.05$. For correlation analysis, leaf expressed on a fresh and dry weight basis, respectively. expressed on fresh and dry weight bases among the genotypes evaluated. Among the 349 germplasm accessions and cultivars screened in 2006, oxalate concentration ranged from 647.2 to $1286.9 \mathrm{mg} / 100 \mathrm{~g}$ fresh weight and 53.4 to $116.2 \mathrm{mg} \cdot \mathrm{g}^{-1}$ dry weight (Fig. 2). This is in line with the results of Kitchen et al. (1964) who found the amount of anhydrous oxalic acid ranging from $5.4 \%$ to $9.8 \%$ on a dry weight bases among 39 spinach breeding lines, hybrids, and $\mathrm{F}_{2}$ populations. From the initial screening, 64 genotypes were further evaluated in 2007. Oxalate content of these genotypes averaged $913.0 \mathrm{mg} / 100 \mathrm{~g}$ in 2006 and $1024.3 \mathrm{mg} / 100 \mathrm{~g}$ in $2007 \mathrm{on}$ a fresh weight basis, and $75.1 \mathrm{mg} \cdot \mathrm{g}^{-1}$ in 2006 and $83.2 \mathrm{mg} \cdot \mathrm{g}^{-1}$ in 2007 on a dry weight basis (Table 1). This shows that besides genotypic effect, environment also has a great influence on oxalate content in spinach.

When expressed on a fresh weight basis, oxalate concentration may be affected by the moisture content of the plant. The oxalate concentration of NSL 4658 was higher than average on a dry weight basis, but was lower than average on a fresh weight basis because the concentration was diluted by its high water content $(89.3 \%$, Table 1$)$. 'Bordeaux' had a low oxalate concentration on a dry weight basis, but showed only average concentration on a fresh weight basis as a result of its low water content (85.0\%). Similarly, the effect of moisture content on carotenoid concentration was reported in lettuce (Mou, 2005). Nevertheless, oxalate concentration on a fresh weight basis was highly correlated with oxalate concentration on a dry weight basis $(r=0.781, P<0.01$; Table 2$)$.

Whether on a fresh weight or on a dry weight basis, two accessions from Syria, PI 445782 (cultivar name Shami) and PI 445784 (cultivar name Baladi), consistently had low oxalate concentrations (Table 1). Many
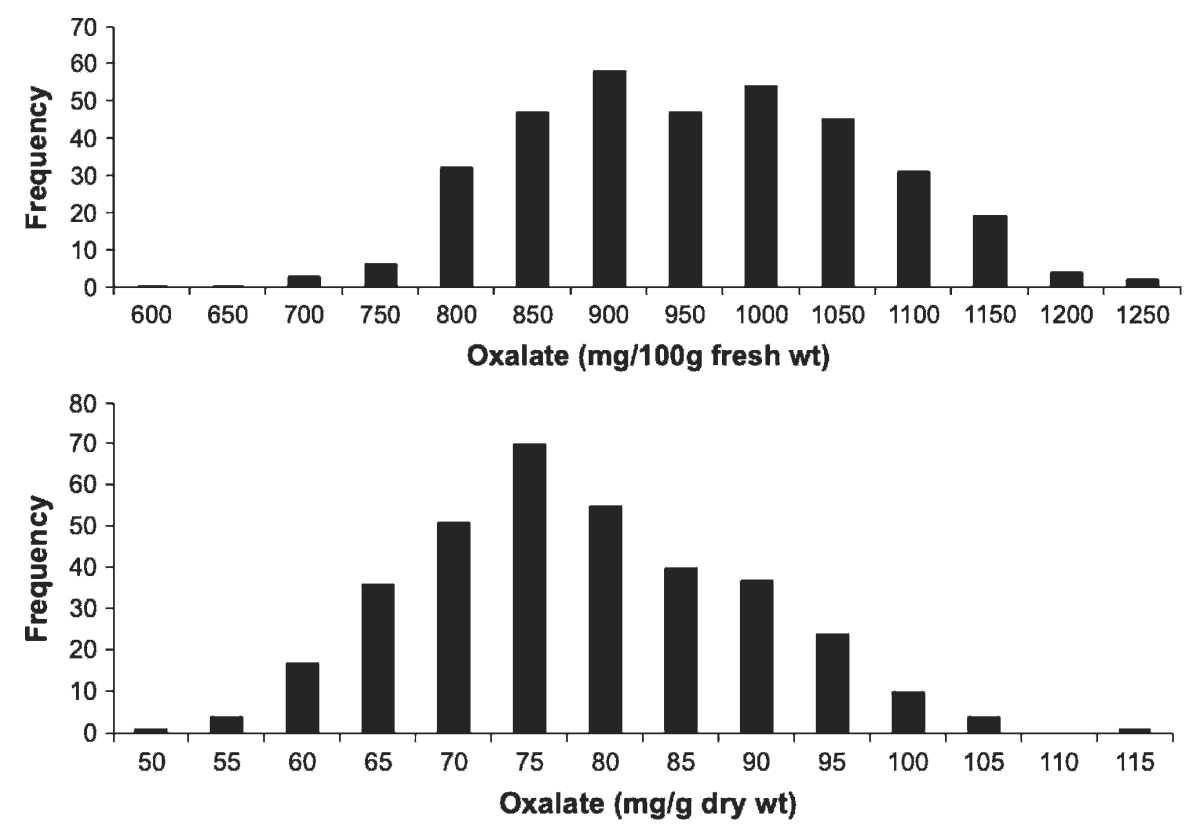

Fig. 2. Frequency distribution of oxalate concentration of 349 spinach accessions screened in 2006 
Table 1. Means of fresh leaf weight per plant, chlorophyll content, moisture, and oxalate concentration expressed on fresh weight and dry weight bases (mg per unit leaf weight) of 64 spinach genotypes tested in 2006 and 2007.

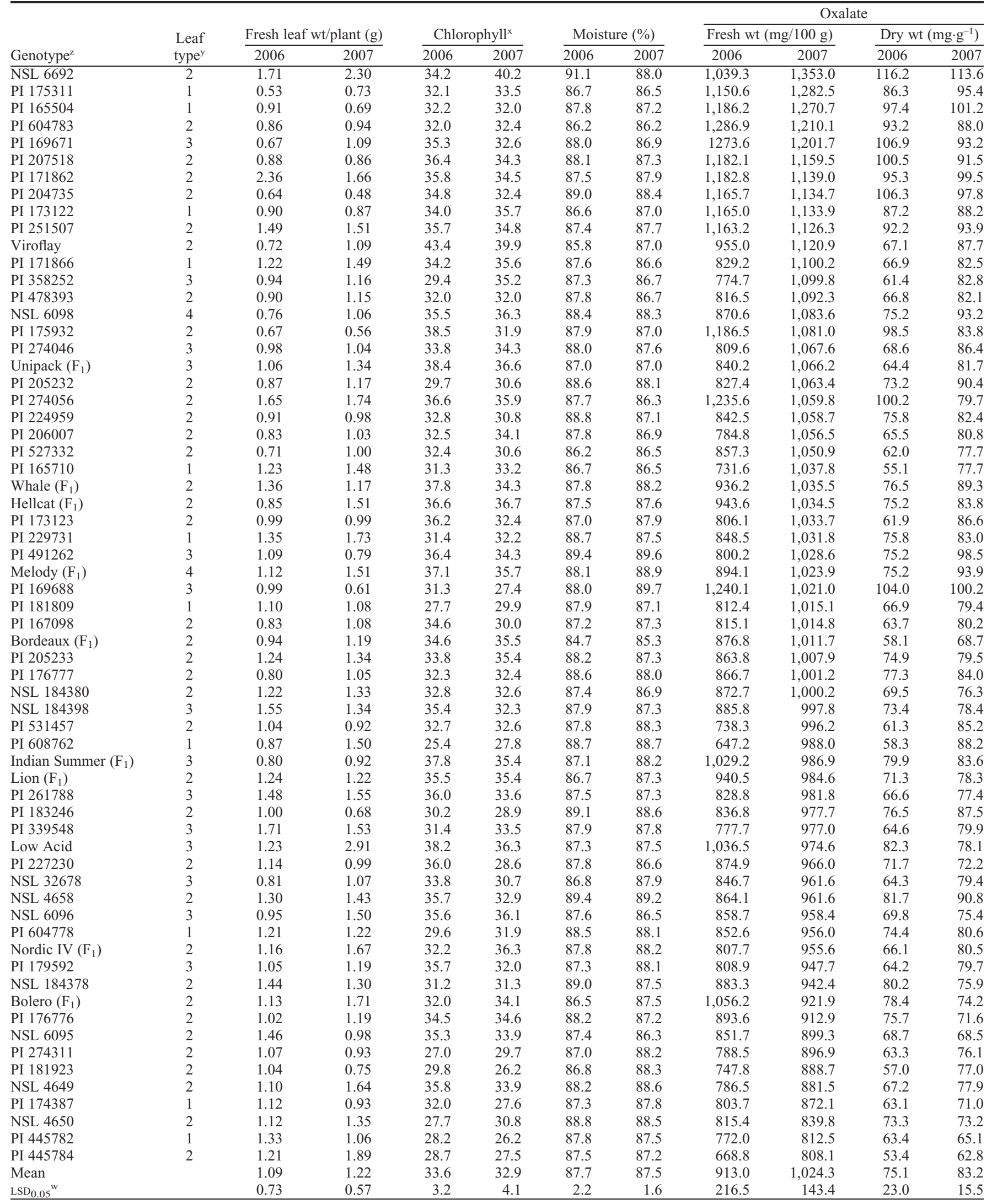

${ }^{\mathrm{z}} \mathrm{PI}$ and NSL are designations of the USDA spinach germplasm collection and the rest are cultivars; $\mathrm{F}_{1}=\mathrm{F}_{1}$ hybrid.

'Leaf type: 1 = flat, 2 = semiflat, 3 = semisavoy, and 4 = savoy.

${ }^{x}$ Chlorophyll readings of Minolta Chlorophyll Meter SPAD-502.

${ }^{\text {w }}$ east significant differences at $P<0.05$. 
Table 2. Phenotypic correlation coefficients $(r)$ between oxalate concentration (on fresh weight and dry weight bases) and other traits calculated from the means of 349 spinach genotypes evaluated in Salinas, $\mathrm{CA}$, in 2006.

\begin{tabular}{lccccc}
\hline Traits & Leaf type & $\begin{array}{c}\text { Fresh leaf } \\
\text { wt/plant }\end{array}$ & Chlorophyll & Moisture (\%) & Oxalate (fresh wt) \\
\hline Fresh leaf & & & & & \\
$\quad$ wt/plant & $0.156^{* *}$ & & & \\
Chlorophyll & $0.309^{* *}$ & -0.022 & & \\
Moisture percent & $0.117^{*}$ & 0.101 & $-0.257^{* *}$ & & \\
Oxalate (fresh wt) & $-0.109^{*}$ & 0.057 & $0.291^{* *}$ & -0.085 & $0.781^{* *}$ \\
Oxalate (dry wt) & -0.017 & $0.119^{*}$ & 0.086 & $0.547^{* *}$ &
\end{tabular}

"** Significant at $P<0.05$ and 0.01 , respectively.

genotypes had lower oxalate concentration than 'Low Acid', a variety claimed to have "very little oxalic acid" (Anonymous, 2008b). The low-oxalate genotypes identified in our experiments are all $S$. oleracea. None of the two $S$. tetrandra and four $S$. turkestanica accessions screened contained low levels of oxalate in the initial (2006) screening and they were excluded from further testing.

Water content was correlated with oxalate concentration on a dry weight basis $(r=$ $0.547, P<0.01)$ but not on a fresh weight basis (Table 2). On the other hand, chlorophyll content was correlated with oxalate content on a fresh weight basis $(r=0.291$, $P<0.01$ ) but not on a dry weight basis. This again shows that when oxalic acid is studied in spinach, it is important to express oxalate concentration on both fresh weight and dry weight bases.

Leaf type had a significant but weak correlation with oxalate concentration on a fresh weight basis $(r=-0.109, P<0.05)$, but showed no association with oxalate concentration on a dry weight basis (Table 2). Kitchen et al. (1964) found that savoy types had lower amounts of oxalates on a dry weight basis than smooth or semisavoy forms in 39 spinach breeding lines, hybrids, and $\mathrm{F}_{2}$ populations. Our study had a total of 349 genotypes from all over the world and contained 46 flat, 191 semiflat, 84 semisavoy, and 28 savoy leaf types.

Leaf type was correlated with chlorophyll content $(r=0.309, P<0.01$; Table 2$)$, suggesting that more savoy types of spinach tend to have higher chlorophyll content. That is conceivable because savoy types generally have thicker and darker green leaves than flat types.

Leaf weight per plant showed a weak correlation with oxalate content on a dry weight basis $(r=0.119, P<0.05)$, but no such correlation with oxalate concentration on a fresh weight basis (Table 2). This suggests that leaf weight per plant and oxalate concentration can be improved independently, and it is possible to combine high leaf yield and low oxalate content in a cultivar. $\mathrm{F}_{1}$ hybrid cultivars grew faster than other open-pollinated accessions but generally had average oxalate concentrations (Table 1). Kaminishi and Kita (2006) found that fastgrowing spinach cultivars contained lower oxalate concentrations. They took plant samples of different cultivars for oxalate analysis at different times, i.e., when a cultivar reached harvest maturity. The fast-growing cultivars probably had less time to accumulate oxalate. They also harvested both leaf blades and petioles for oxalate analysis. Savoy leaf types tend to grow slower and have shorter petioles, whereas flat leaf types generally grow faster and have longer petioles that have lower oxalate concentration than leaf blades. However, the leaf types of the cultivars were not described in their report. We harvested only leaf blades from all spinach genotypes at the same time ( 5 weeks after planting).

Because of the health benefits of consuming fruits and vegetables, there is great interest in reducing the level of antinutritional oxalate in spinach. Our study demonstrated that a wide range of genetic variability in oxalate content exists in spinach germplasm. Two accessions from Syria, PI 445782 ('Shami') and PI 445784 ('Baladi'), may be used as sources of low oxalate concentration in a spinach breeding program. Oxalate concentration had little correlation with leaf type and leaf weight per plant, suggesting that it is possible to combine low oxalate and high yield in different types of spinach. These results suggest that genetic improvement of spinach for a low level of oxalate is feasible.

\section{Literature Cited}

Anonymous. 2008a. Sun rise and sun set in Salinas. 19 May 2008. <http://www.timeanddate.com/ worldclock/astronomy.html?n=883>.
Anonymous. 2008b. Spinach, p. 26. In: Bountiful gardens 2008 catalog. Ecology Action, Willits, CA.

Bataille, P. and A. Fournier. 2001. Calcium supply in calcium lithiasis. Med. Nutr. 37:9-12.

Elia, A., P. Santamaria, and F. Serio. 1998. Nitrogen nutrition, yield and quality of spinach. J. Sci. Food Agr. 76:341-346.

Hodgkinson, A. 1977. Oxalic acid in biology and medicine. Academic Press, London, UK.

Kaminishi, A. and N. Kita. 2006. Seasonal change of nitrate and oxalate concentration in relation to the growth rate of spinach cultivars. HortScience 41:1589-1595.

Kitchen, J.W., E.E. Burns, and B.A. Perry. 1964. Calcium oxalate content of spinach (Spinacia oleracea L.). Proc. Amer. Soc. Hort. Sci. 84: 441-445.

Kohman, E.F. 1939. Oxalic acid in foods and its behavior and fate in diet. J. Nutr. 18: 233-246.

Massey, L.K., H. Roman-Smith, and R.A.L. Sutton. 1993. Effect of dietary oxalate and calcium on urinary oxalate and risk of formation of calcium oxalate kidney stones. J. Amer. Diet. Assn. 93:901-906.

Maynard, D.N., A.V. Barker, P.L. Minotti, and N.H. Peck. 1976. Nitrate accumulation in vegetables. Adv. Agron. 28:71-118.

Moir, K.W. 1953. The determination of oxalic acid in plants. Queensland J. Agr. Sci. 10:1-3.

Morelock, T.E. and J.C. Correll. 2008. Spinach, p. 189-218. In: Prohens, J. and F. Nuez (eds.). Handbook of plant breeding, Volume 1, Vegetables I, Asteraceae, Brassicaceae, Chenopodicaceae, and Cucurbitaceae. Springer, New York, NY.

Mou, B. 2005. Genetic variation of $\beta$ - carotene and lutein contents in lettuce. J. Amer. Soc. Hort. Sci. 130:870-876.

National Agricultural Statistics Service, USDA. 2006. Spinach national statistics. 26 June 2007. <http://www.nass.usda.gov/QuickStats/ index2.jsp $>$.

Oke, O.L. 1969. Oxalic acid and plants and in nutrition. World Rev. Nutr. Diet. 10: 262-303.

Okutani, I. and N. Sugiyama. 1994. Relationship between oxalate concentration and leaf position in various spinach cultivars. HortScience 29:1019-1021.

Palaniswamy, U.R., B.B. Bible, and R.J. McAvoy. 2004. Oxalic acid concentrations in purslane (Portulaca oleraceae L.) is altered by the stage of harvest and the nitrate to ammonium ratios in hydroponics. Sci. Hort. 102:267-275.

Pandey, S.C. and G. Kalloo. 1993. 23: Spinach Spinacia oleracea L., p. 325-336. In: Kalloo, G. and B.O. Bergh (eds.). Genetic improvement of vegetable crops. Pergamon Press, Oxford, UK.

USDA. 1984. Oxalic acid content of selected vegetables. In: Agriculture handbook, No. 811 , Vegetables and vegetable products. 15 Jan. 2008. <http://www.nal.usda.gov/fnic/food comp/Data/Other/oxalic.html>. 